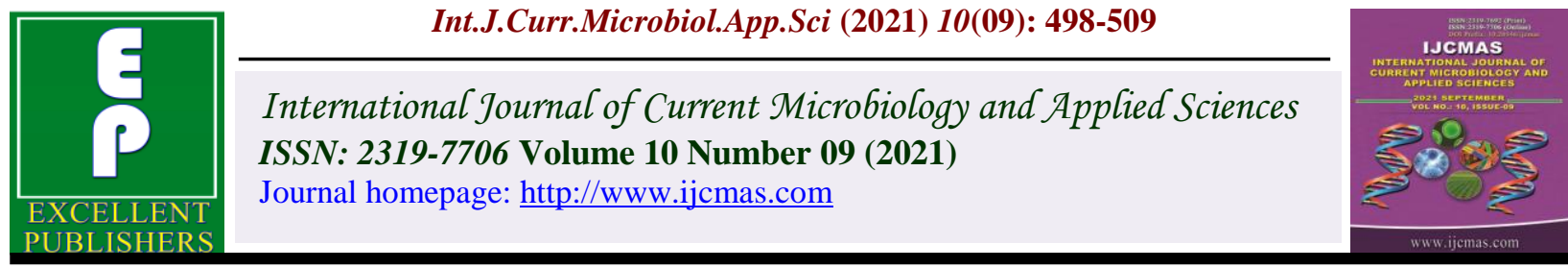

\title{
Invitro Antimicrobial and Antioxidant Activities of Salvadora persica (Meswak) Roots, Leaves and Stems Extracts
}

\author{
Dipeshkumar Patel" and Falaknaaz Shaikh
}

Shri Alpesh N. Patel Post Graduation Institute of Science and Research, Anand, India

*Corresponding author

\section{A B S T R A C T}

Keywords

Meswak tree;

Antimicrobial activity; Aqueous extracts (hot and cold extraction)

Article Info

Accepted:

20 August 2021

Available Online:

10 September 2021
As microorganisms have developed the inherent ability to develop and adopt a mechanism of resistance against antibiotic. The harmful side effect of antibiotic including their cost of drug development have slowly shifted toward the plant derived phytochemical based medicines. Screening of antimicrobial property of medicinal plants $S$. persica gives a positive result against the different species of bacteria (S. aureus, P. aeruginosa) and fungi (A.niger, Fusarium). Firstly, a study of phytochemicals shows that the important part to prevent and protect the plant against the microorganisms. Secondly, the importance of phytochemicals of S.perica provide the information about the compound which are responsible for the antimicrobial activity like alkaloids, phenolics, flavonoids etc. Finally, an antioxidant activity involves in the prevention of plant cell tissue damage. Antioxidant activity is measured by DPPH. The total phenolics content of this plant was good and there for this, has high antimicrobial activity. The S.persica has many applications in mouth associated problems, useful to produce antiplaque, analgesic, anticonvulsant, antimycotic, cytotoxic, antifertility, deobstruent, carminative, diuretic, and also applicable in rheumatism.

\section{Introduction}

The plants are also vulnerable to microorganisms like bacteria, fungi, protozoa (3) (16). The main causative agent of plant disease are the bacteria and fungi (2) (4). So, the plants have some antimicrobial and antifungal activity for protection against bacteria and fungi. Maintain the population rate (mortality and morbidity). Nowadays, bacteria, fungi, protozoa and some other microorganisms resist to therapeutic agent (5). So, overcome to these problems or less side effect we use a medicinal compound (11) (14). Medicinal plant as a source of medicinal compound important for the treatment of disease like cancer.

Salvodara persica $L$. is belong to the family of Salvodaraceae. In 1749 term salvodara set by 
Dr. Laurent Garcin. The term persica is used to indicate Persia while standard author abbreviation L. indicate the father of modern taxonomy, Carl Linnaeus. S. persica is large well branched evergreen tree with soft whitish yellow wood, leaves (3.8 to 6.3 by 2 to 3.2 $\mathrm{cm})$ greenish yellow flower and fruit red while ripe (9) (10) (17).

S.persica can survive in extreme condition and capable of tolerating very dry environments to high saline soil, it was found in arid coastal regions, saline lands, desert flood plains and grassy savannahs.

In different countries plant display some variations in it is distributional behavior it may due to changes in water resources, climate factors and anthropogenic pressures along the elevation gradient. S.persica is commonly known as miswak tree most common source of miswak and used as chewing sticks across the world the meaning of miswak is tooth cleaning stick (6) (8) (19).

In English the miswak is known as natural tooth brush miswak is trimmed at one end and of the tip forming an exposed end which is then chew to form a brush. Also, the WHO has recommended and encouraged to use these sticks for oral hygiene.

Traditional uses of $S$. persica for various purposes such as food, fuel, cosmetics, oral hygiene, for instance the leaves are cooked as sauce and eaten as salads. The flowers were found to be a good source of nectar for honey bee and it is strongly believed that the honey of $S$. persica has high medicinal value (1) (5) (20). Different parts of the plants like root, stem, leaves, flowers and fruits have been used in variety of preparation for internal and external uses against the various diseases.

The purpose of this study is to extract the antimicrobial agents by $S$. persica. This extract was further tested for their antimicrobial as well as antioxidant activity such as on microorganism and on fungi.

\section{Materials and Methods}

\section{Preparation of the plant extract}

The freshly collect the plant parts of S. persica from the Anand Agriculture University. The plant parts washed with distilled water and air dried at $40^{\circ} \mathrm{C}$ by using hot air oven or dried at direct sunlight for 1 or 2 days. Then, make a powder by using grinder. The powder was collected in zip bag to prevent the moisture.

\section{Plant sample extraction (Aqueous)}

The plant sample was extracted by using aqueous method and solvent extraction method.

\section{Hot water extraction}

Take 5 to $10 \mathrm{gm}$ of plant powder sample and add it to in $100 \mathrm{ml}$ of distilled water in a conical flask and incubate to water bath at $80^{\circ} \mathrm{C}$ for 2 to 3 hours. After that, the mixture was homogenized and filtered by using muslin cheese cloth and sample was proceed into rotary vacuum evaporator for evaporation of water and sample extraction.

The temperature of rotary vaccum evaporator is depends on the boiling point of solvent to be used. After the evaporation, the sample was filtrated (Whatman filter paper) and collected in black screw cap bottle and stored in refrigerator.

\section{Cold water extraction}

Take 5 to $10 \mathrm{gm}$ of the dried powder sample and added to $100 \mathrm{ml}$ distilled water in a conical flak and incubate into orbital shaker incubator at $140 \mathrm{rpm}$ for overnight. Next day, 
the mixture was homogenized and filtrated with use of muslin cheese cloth and proceed it in to rotary vacuum evaporator and after that the extract must filtrated with (Whatman filter paper) and the final extract collect in to the black screw cap bottle and stored in to refrigerator.

\section{Plant sample extraction (Solvent)}

Plant extract is extracted by using Soxhlet extractor with high efficiency to analyze the phytochemicals present in the extract and by using this extract we can perform the different assay. This temperature used in this method is based on the boiling point of solvent.

The solvent used for the extraction of plant sample are Methanol(boiling temperature is $64.7^{\circ} \mathrm{C}$ or $\left.65^{\circ} \mathrm{C}\right)$ and hexane $\left(69^{\circ} \mathrm{C}\right)$.

Different solvent used because some phytochemicals are dissolved in polar and some are dissolved in non-polar solvent.

\section{Phytochemical Analysis}

\section{Test for coumarins}

Take $2 \mathrm{ml}$ of plant extract and add $10 \%$ $\mathrm{NaOH}$, formation of yellow color indicates the presence of coumarins.

\section{Test for Anthocyanin}

Take $2 \mathrm{ml}$ of extract and add 2N HCL and few drops of ammonia, if the anthocyanin is present in the sample the pink -red color turning to blue-violet color.

\section{Test for steroids (Libermann Burchard Test)}

Take $1 \mathrm{ml}$ of extract and add $10 \mathrm{ml}$ chloroform and in that add equal amount of $\mathrm{H}_{2} \mathrm{SO}_{4}$ positive result gives upper layer red, while lower layer yellow with green fluorescence.

\section{Test for saponins}

Take $2 \mathrm{ml}$ of extract and add $6 \mathrm{ml}$ of distilled water and then shaken it vigorously, foam was observed when the sample has saponins.

\section{Test for terpenoids}

$2 \mathrm{ml}$ of extract treated with $2 \mathrm{ml}$ of acetic anhydride and then add few drops of $\mathrm{H}_{2} \mathrm{SO}_{4}$, positive result give blue, green ring formation.

\section{Test for tannins (Braymer's Test)}

Take $2 \mathrm{ml}$ of extract and allowed it to react with $10 \%$ alcoholic ferric chloride solution, positive result gives the formation of blue, green color.

\section{Test for phenolics}

Add Few drops of extract in to $5 \%$ aqueous ferric chloride and when this test is positive deep blue or dark color form.

\section{Test for flavonoids (Alkaline reagent test)}

$2 \mathrm{ml}$ of extract treated with $1 \mathrm{~N}$ sodium hydroxide solution and give intense yellow color if, sample has flavonoids.

\section{Test for alkaloids (Mayer's reagent)}

Add $2 \mathrm{ml}$ of extract with few drops of Mayer's reagent and if, sample contain alkaloids than it will give white creamy precipitates.

\section{Test for reducing sugar}

Take $0.5 \mathrm{ml}$ of sample and add $5 \mathrm{ml}$ of benedict reagent, boil it in boiling water bath for $1 \mathrm{~min}$ if the sample has reducing sugar, the solution form brick red color precipitates. 


\section{Test microorganisms}

The bacterial (S. aureus, $P$. aeruginosa) and fungal (A. niger and Fusarium) strain was collected from Shri Alpesh N Patel Post Graduation Institute of Science and Research, Anand.

\section{Culture media and inoculums}

The N-agar media used for the Anti-bacterial activity and PDA media was used for Antifungal activity. The bacterial culture was inoculated in the nutrient broth and incubated overnight to allow the growth.

\section{Antibiotics}

The antibiotic was used as a positive control in antimicrobial activity. In this activity Ampicillin was used as positive control and the concentration was $10 \mathrm{mg} / \mathrm{ml}$. In anti-fungal activity the Fluconazole was used, the concentration was $10 \mathrm{mg} / \mathrm{ml}$.

\section{Antimicrobial screening}

The antimicrobial activity of different parts extract carried out by agar well diffusion method.

\section{Antibacterial activity}

The Antibacterial activity carried out by using agar well diffusion method and test microorganisms. The negative control of Antibacterial activity are Methanol, Hexane and distilled water.

\section{Antifungal activity}

The Antifungal activity was carried out by using well diffusion method. In this method the first step is growth of fungus on selective media, then make a suspension of it. If, fungus is sporulated then count the spores by hemocytometer and after that make a suspension which is used for the assay.

Take an aliquot of $0.1 \mathrm{ml}$ of suspension and spread it on the appropriate media, then make a well. Wells were filled with different parts extracts, in which for negative control the solvent and distilled water used and for positive control the Fluconazole was used.

Incubate the plates in incubator for 6 to 7 days at $25^{\circ} \mathrm{C}$ to $30^{\circ} \mathrm{C}$. If the sample has Antifungal activity, then the zone of inhibition was observed after the incubation time.

\section{Antioxidant activity}

The antioxidant activity was determined by 2 , 2 - diphenyl-1-picrylhydrazyl (DPPH) Radical scavenging method.

The anti-oxidant activity of different extract was measured in terms of $\mathrm{H}^{+}$donating or radical scavenging ability, using the stable radical DPPH. The different aliquots of extracts and $2 \mathrm{ml}$ of DPPH in each tube was put in dark for 15 to 20 minutes and then take O.D at $517 \mathrm{~nm}$.

\section{Total phenolics}

Take 0.5 to $1 \mathrm{gm}$ of plant sample and grind it with mortar and pestle in 10times volume of ethanol. Centrifuge the homogenate at 10,000 RPM for $20 \mathrm{~min}$, save the supernatant. Evaporate the supernatant to dryness.

Dissolve the residue in a known volume of distilled water $(5 \mathrm{ml})$, pipette out different aliquots into test tubes. Make up the volume in each tube to $3 \mathrm{ml}$ with water, add $0.5 \mathrm{ml}$ of FCR reagent. After $3 \mathrm{~min}$, add $2 \mathrm{ml}$ of $20 \%$ $\mathrm{Na}_{2} \mathrm{CO}_{3}$ solution to each tube, boil it in the boiling water bath and after that take O.D at 650 . 


\section{Results and Discussion}

\section{Phytochemical analysis of plant extracts}

The study of phytochemicals of S. Persica shows that Alkaloids, Flavonoids, Tannins, Saponins, Terpenoids, Steroids, reducing sugar, Coumarins, Phenolics are present (10) (13).

\section{Anti-microbial activity}

\section{Anti-bacterial activity}

In S.persica the active compound benzyl isothiocyanate (BITC) exhibited the strong bactericidal effect against the Gram-negative bacteria (18) (22). The screening of antimicrobial activity of the $S$. persica shows the antibacterial activity against the $S$. aureus, $P$. aeruginosa

\section{Antifungal activity}

Antifungal activity was observed against $A$. nigerin S.persica, and there was no antifungal effect observed against fusarium (9). The extraction of $S$. persica gives the antifungal activity against $A$. niger, and some parts give antifungal activity against the Fusarium. The fluconazole antibiotic used as positive control, concentration is $10 \mathrm{mg} / \mathrm{ml}$.

\section{Antioxidant activity}

After screening out the antioxidant activity, the methanol extraction of $S$. persica (Root) gives high antioxidant activity as compare to other parts of plants (17) (21). It also shows the absorbance of Ascorbic acid increase with increasing of concentration of ascorbic acid. The radical scavage activity of ascorbic acid increase after 30 min of incubation in dark condition (15) (16).

Table.1 Phytochemical analysis of aqueous plant extract

\begin{tabular}{|c|c|c|c|c|c|c|c|}
\hline Parts name & $\begin{array}{c}\text { Type of } \\
\text { extract }\end{array}$ & Coumarins & Steroids & Saponins & Tannins & Phenolics & Flavonoids \\
\hline S. persica & & & & & & & \\
\hline Leaves & Hot & + & - & - & + & - & + \\
& Cold & + & - & - & - & - & + \\
\hline Twigs & Hot & - & - & - & - & - & + \\
& Cold & + & - & - & - & + & - \\
Root & Hot & + & - & - & + & - & - \\
& Cold & + & - & + & - & + & - \\
\hline
\end{tabular}

NB: The meaning of ' + ' is Positive/Present whereas, the meaning of "_"” is Negative/Absent.

Table.2 Phytochemical analysis of Methanol plant extract

\begin{tabular}{|c|c|c|c|}
\hline Test & Root & Leaves & Stem \\
\hline Steroids & + & + & + \\
\hline Coumarins & + & - & - \\
\hline Saponins & + & + & + \\
\hline Alkaloids & + & - & - \\
\hline Flavonoids & - & - & + \\
\hline Tannins & - & + & + \\
\hline Phenolics & - & + & + \\
\hline Reducing sugar & + & + & - \\
\hline Terpenoids & + & - & - \\
\hline
\end{tabular}


Table.3 Phytochemical analysis of Hexane plant extract

\begin{tabular}{|c|c|c|c|}
\hline Test & Root & Leaves & Stem \\
\hline Steroids & - & - & - \\
\hline Coumarins & - & - & - \\
\hline Saponins & - & - & - \\
\hline Alkaloids & - & - & - \\
\hline Flavonoids & - & - & - \\
\hline Tannins & + & - & - \\
\hline $\begin{array}{c}\text { Reducing } \\
\text { sugar }\end{array}$ & + & - & - \\
\hline
\end{tabular}

Table.4 Antibacterial activity of S.persica against S. aureus (mm)

\begin{tabular}{|c|c|c|}
\hline Sample parts & Extraction method & Zone of inhibition (mm) \\
& Hot & $\mathbf{3}$ \\
S. stem & Cold & - \\
\hline S. root & Hot & 3 \\
& Cold & - \\
S. leaves & Hot & - \\
& Cold & - \\
\hline
\end{tabular}

Table.5 Antibacterial activity of S.persica against the P.aeruginosa(mm)

\begin{tabular}{|c|c|c|}
\hline S. stem & Hot & - \\
& Cold & $\mathbf{4}$ \\
\hline S. root & Hot & 8 \\
& Cold & 7 \\
\hline S. leaves & Hot & 13 \\
& Cold & - \\
\hline
\end{tabular}

Table.6 Antibacterial activity of methanolic extracts of S.persica

\begin{tabular}{|c|ccc|cc|}
\hline S. persica & \multicolumn{2}{|c|}{ S. aureus $(\mathbf{m m})$} & \multicolumn{2}{c|}{ P. aeruginosa $(\mathbf{m m})$} \\
\hline Root & 13 & 11 & 14 & 15 \\
\hline Stem & 13 & 09 & - & - \\
\hline Leaves & - & 12 & - & 12 \\
\hline
\end{tabular}

Table.7 Antibacterial activity of Hexane extracts of S.persica

\begin{tabular}{|c|c|c|}
\hline $\begin{array}{c}\text { S. persica } \\
(\mathbf{B})\end{array}$ & $\begin{array}{c}\text { S. aureus } \\
(\mathbf{m m})(\mathbf{B})\end{array}$ & $\begin{array}{c}\text { P. aeruginosa } \\
(\mathbf{B})\end{array}$ \\
\hline Root & 08 & 09 \\
\hline Leaves & 04 & - \\
\hline Stem & 06 & 09 \\
\hline
\end{tabular}


Table.8 Antifungal activity of different extracts of $S$. persica

\begin{tabular}{|c|c|c|c|}
\hline $\begin{array}{c}\text { Name of plant } \\
\text { S.persica(A) }\end{array}$ & Type of extraction & A. niger & Fusarium \\
\hline (A)Leaves & Hot & - & - \\
& Cold & - & - \\
& Methanol & - & - \\
\hline Hexane & Hot & - & - \\
& Cold & - & - \\
& Methanol & - & - \\
& Hexane & - & - \\
& Hot & - & $+(6 \mathrm{~mm})$ \\
& Cold & - & $+(3 \mathrm{~mm})$ \\
\hline & Methanol & - & - \\
\hline
\end{tabular}

Graph.1 Phytochemicals of S persica

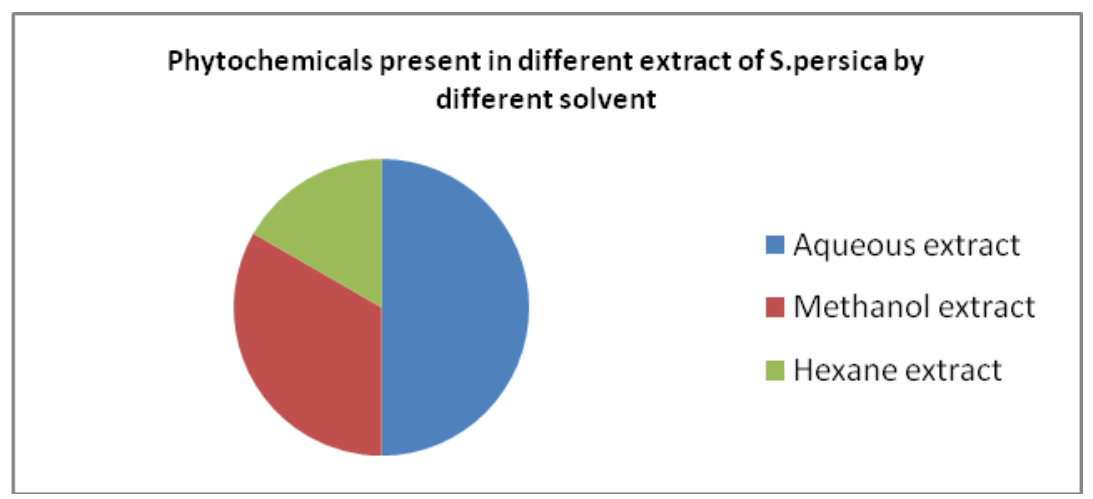

Graph.2 Antioxidant activity of $S$. persica(ascorbic acid)

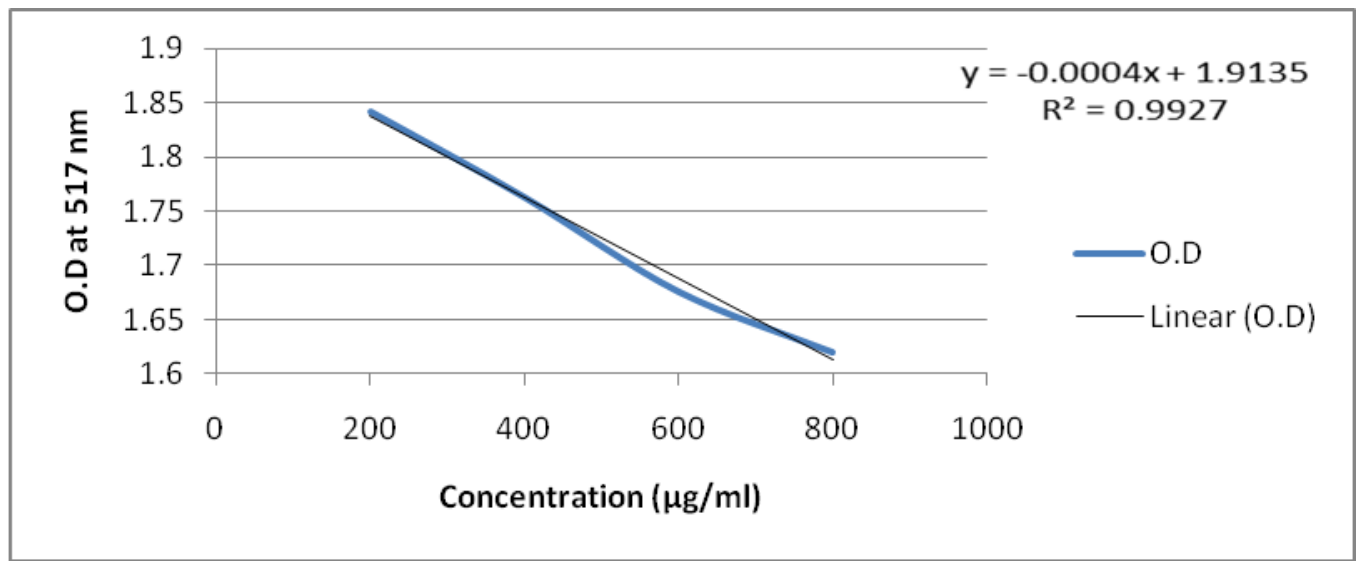


Graph.3 Antioxidant activity of S. persica (Stem)

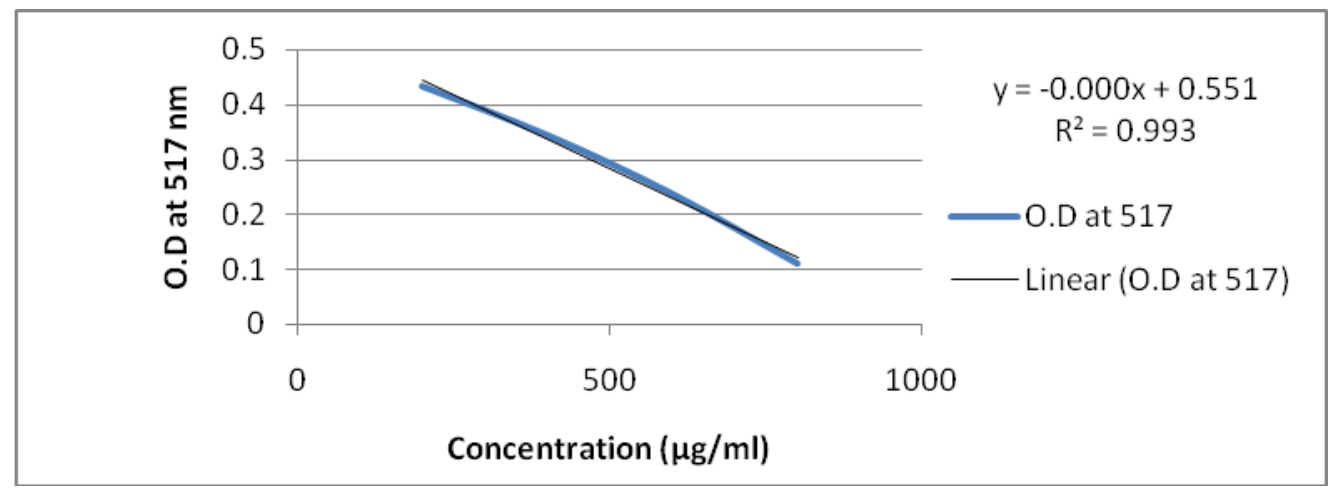

Phytochemical Analysis Images

Image. 1 Tannin

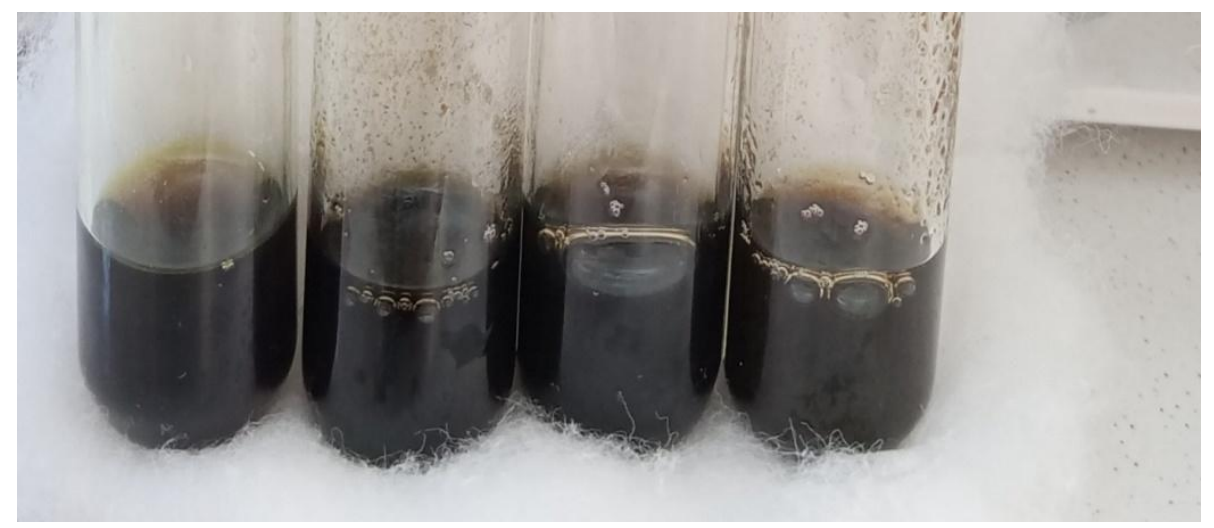

Image.2 Saponins
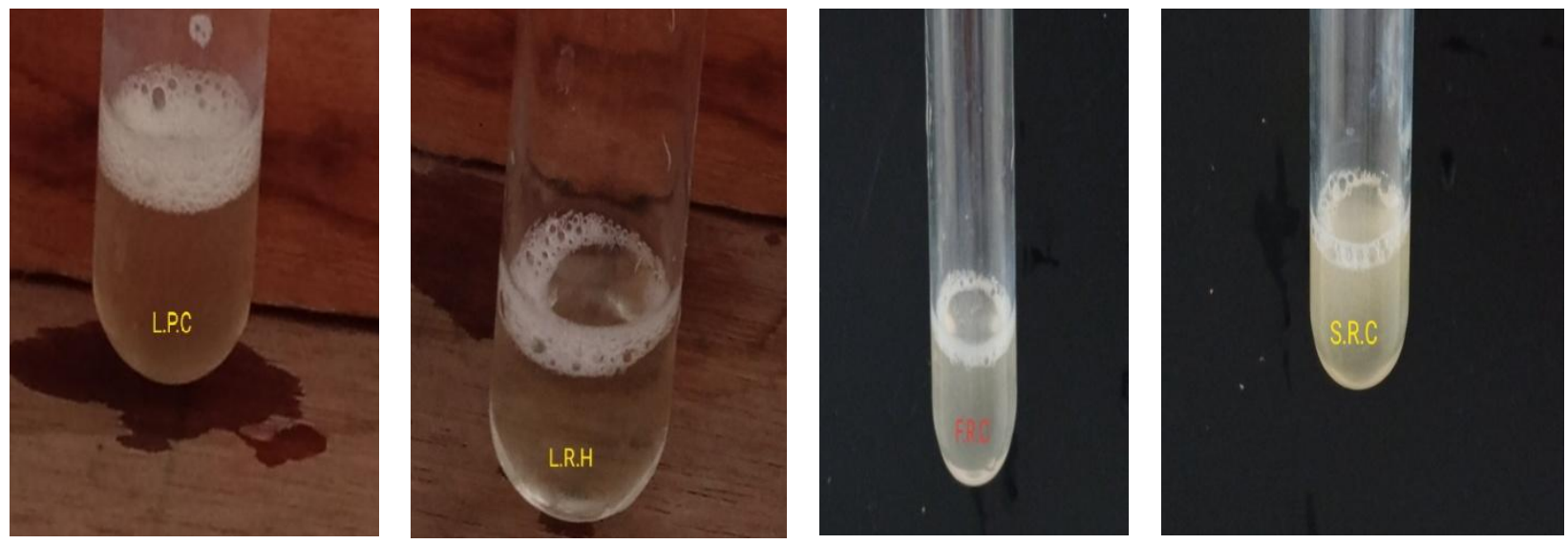


\section{Image.3 Steroids}
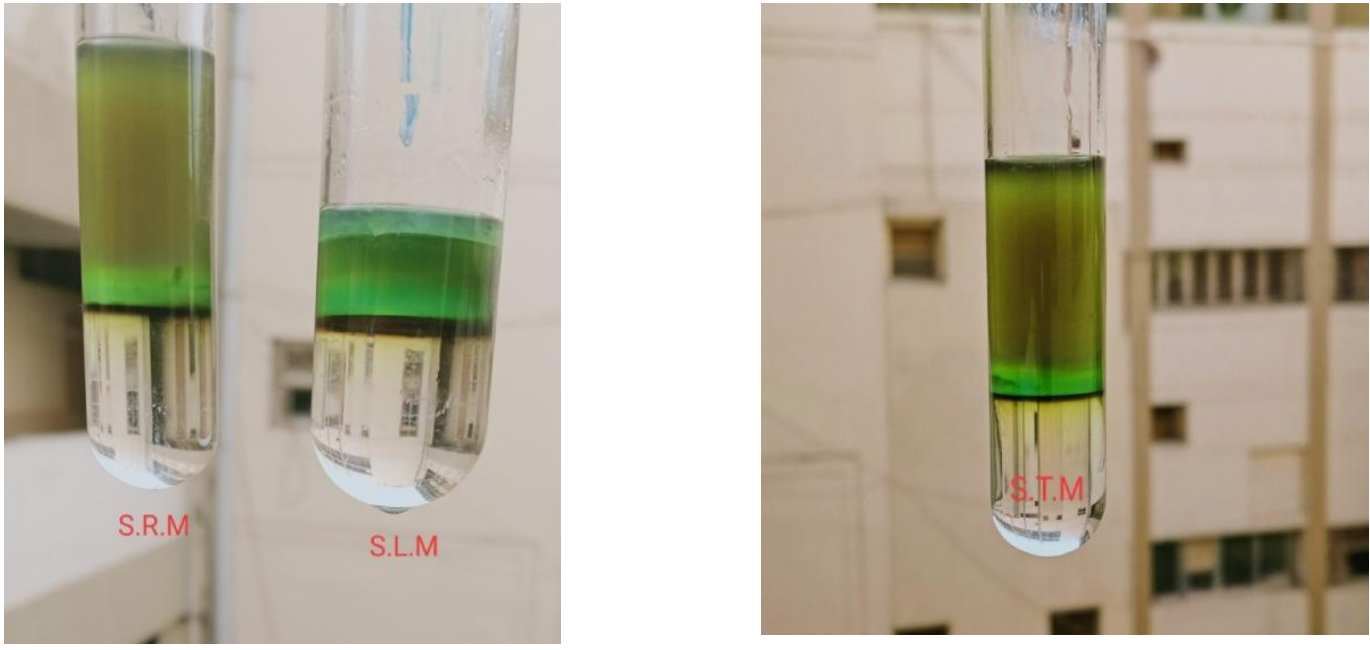

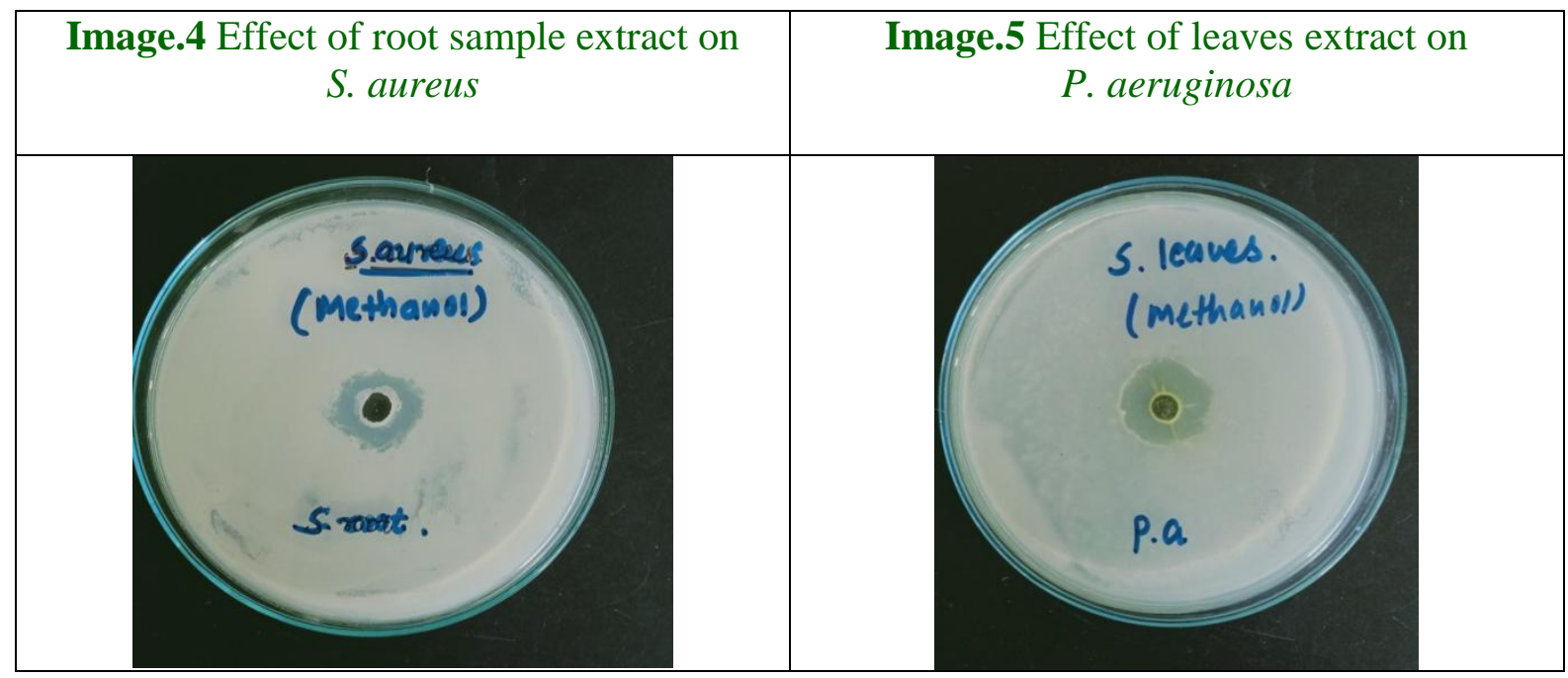

Image.6 Anti-fungal activity of plant extracts against Fusarium and A. niger

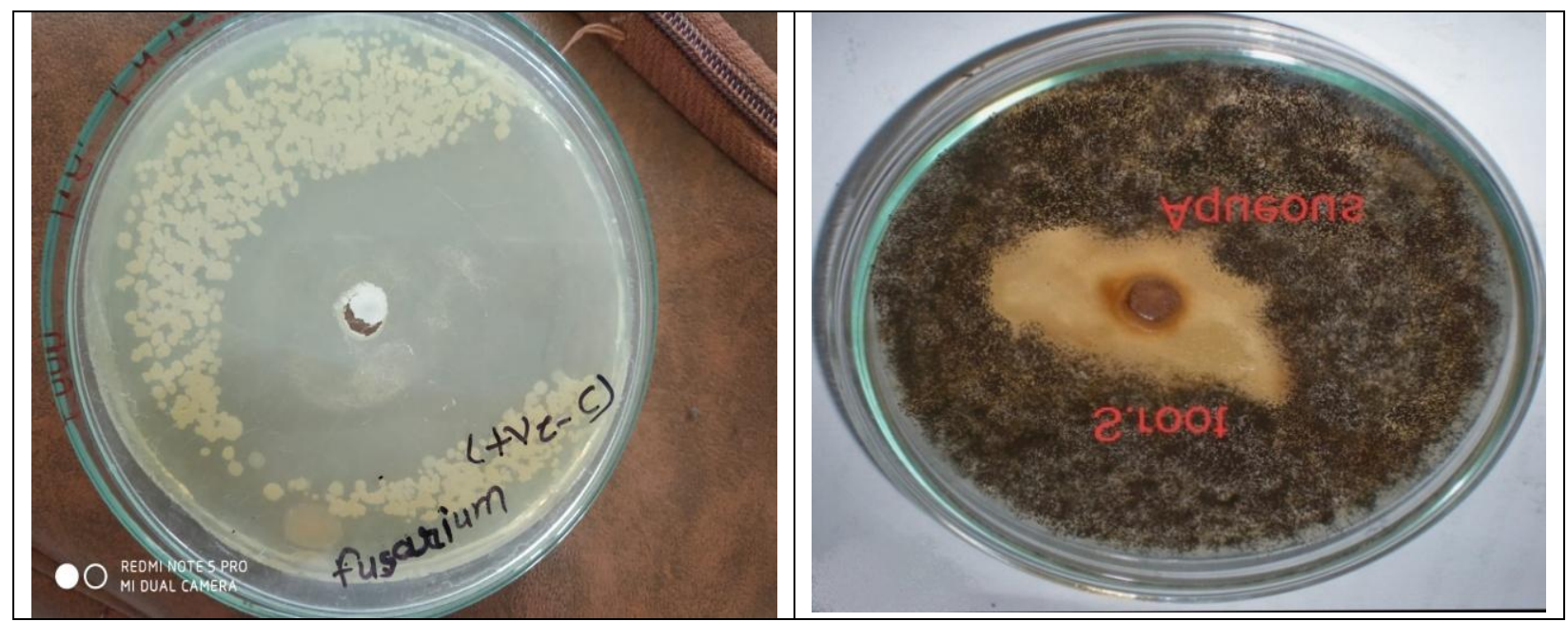


Image.7 Antioxidant activity of S. persica (Stem)

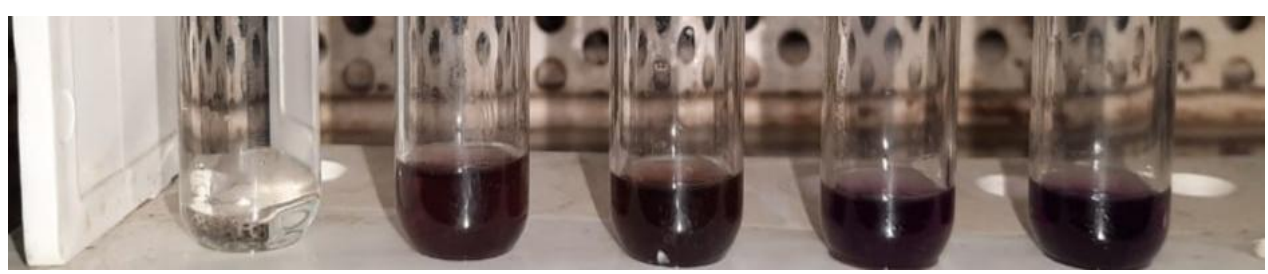

Image.8 Antioxidant activity of S.persica (Root)

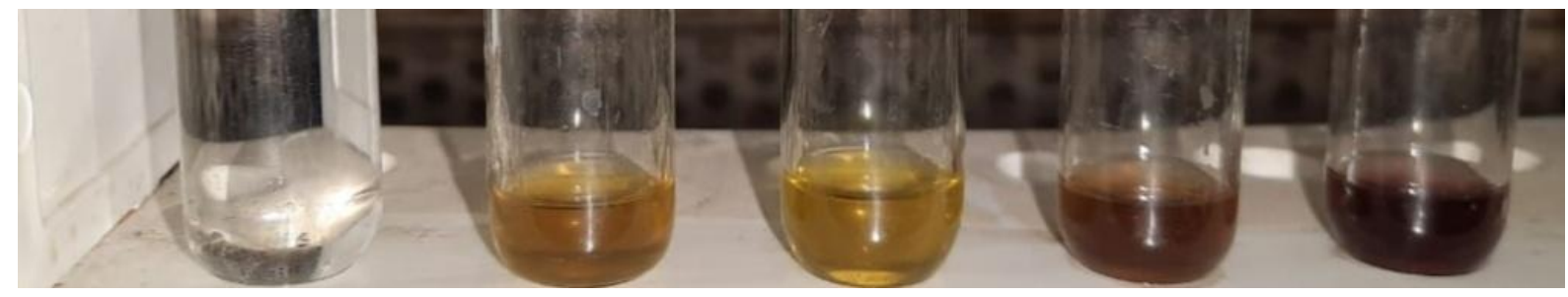

Image.9 Total phenolics

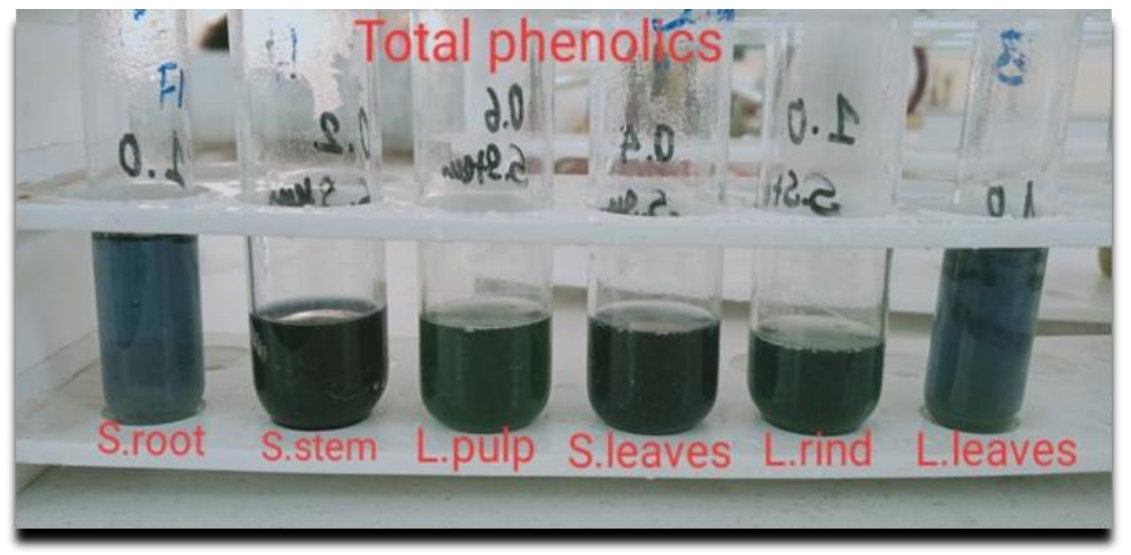

As microorganisms have developed the inherent ability to develop and adopt a mechanism of resistance against antibiotic. The harmful side effect of antibiotic including their cost of drug development have slowly shifted toward the plant derived phytochemical based medicines.

The screening of antimicrobial property of $S$. persica gives good results against different species of bacteria (S. aureus, P. aeruginosa) and fungi (A. niger, Fusarium). The study of phytochemicals shows the important part to prevent and protect the plant against the microorganisms. Another importance of phytochemicals of $S$. persica provide the information about the compound which are responsible for antimicrobial activity like Alkaloids, Phenolics, Flavonoids etc. The antioxidant activity was involved in the prevention of plant cell tissue damage. Antioxidant activity is measured by DPPH. The total phenolics content of this plant was good and there for this has a high antimicrobial activity. The S.persica have many applications in mouth related problems, useful to produce antiplaque, analgesic, anticonvulsant, antimycotic, cytotoxic, antifertility, deobstruent, carminative, diuretic, and also applicable in rheumatism. 


\section{References}

1. AI-Bagieh $\mathrm{N}$ H (1992) Antiherpes simplex virus type 1 activity of benzylisothiocyanate. Biomed Lett 47: 6770 .

2. Abdillahi H S, Stafford G I, Finnie J F, Staden J V (2010) Ethnobotany, phytochemistry and pharmacology of Podocarpus sensus latissimo (S.I). South Afr J Bot 76: 1-24.

3. Al-Quran S (2008) Taxonomical and pharmacological survey of therapeutic plants in Jordan. J Nat Prod 1: 10-26.

4. Alali F, Al-Lafi T (2003) GC-MS analysis and bioactivity testing of the volatile oil from the leaves of the toothbrush tree Salvadora persica L. Nat Prod Res 17: 189-194.

5. Almas K (2002) The effect of Salvadora persica extract (miswak) and chlorhexidine gluconate on human dentin: A SEM study. J Contemp Dent Prac 3: 2735.

6. Almas K, Skaug N, Ahmad I (2005) An in vitro antimicrobial comparison of miswak extract with commercially available nonalcohol mouth rinses. Int J Dent Hyg 3: 18-24.

7. Alali F, Hudaib M, Aburjai T, Khairallah K, Al-Hadidi N (2005) GC-MS Analysis and antimicrobial activity of the essential oil from the stem of the jordanian toothbrush tree Salvadora persica. Pharmaceu Biol 42: 577-580.

8. Ashraf Taha Khalil (2006) Benzylamides from Salvadora persica. Arch Pharm Res 29: 952-956.

9. Abdel-Wahab S M, Selim M A, EI-Fiki N $M$ (1990) Investigation of the flavonoid content of Salvadora persica L. Bull Fac Pharm (Cairo Univ) 28: 67-70.

10. Deshpan R, Kale A, Ruikar A, Panvalkar P, Kulkarni A, et al., (2011) Antimicrobial activity of different extracts of Juglans regia 1. against oral microflora.
Int J Pharm Sci 3: 200-201.

11. Garboui S S, Borg-Karlson A K, Palsson K (2009) Tick repellent properties of three Libyan plants. J Med Entomol 46: 14151419.

12. Huang S H, Wu L W, Huang A C, Yu C C, Lien J C, et al., (2012) Benzyl isothiocyanate (BITC) induces G2/M phase arrest and apoptosis in human melanoma A375.S2 cells through reactive oxygen species (ROS) and both mitochondria-dependent and death receptor-mediated multiple signaling pathways. J Agric Food Chem 60: 665675.

13. Kamil M, Jayaraj AF, Ahmed F, Gunasekhar C, Samuel S, et al., (1999) Pharmacognostic and phytochemical studies on Salvadora persica. J Pharm Pharmacol 227: 51-58.

14. Kamel M S, Ohtani K, Assaf MH (1992) Lignan glycosides from stems of Salvadora persica. Phytochem 31: 24692471.

15. Malik S, Ahmad S S, Haidar S I, Muzaffar A (1987) Salvadoricine -A new alkaloid from the leaves of Salvadora persica. Tetrahedron Lett 28: 163-164.

16. Malik S, Ahmad S S, Haidar S I, Muzaffar A (1987) Salvadoricine -A new alkaloid from the leaves of Salvadora persica. Tetrahedron Lett 28: 163-164.

17. Noumi E, Snoussi M, Hajlaoui H, Valentin E, Bakhrouf A (2010) Antifungal properties of Salvadora persica and Juglans regia L. extracts against oral Candida strains. Eur J Clin Microbiol Infect Dis 29: 81-88.

18. Noumi E, Snoussi M, Trabelsi N, Hajlaoui H, Ksouri R, et al., (2011) Antibacterial, anticandidal and antioxidant activities of Salvadora persica and Juglans regia L. extracts. J Med Plant Res 5: 4138-4146.

19. Rajesh V, Suresh P, Anil B, Brijesh K, Priyanka P (2009) Salvadora persica L (Tooth Brush Tree): A Review. J PR 2: 
1809-1812.

20. Ray A B, Chand L, Dutta S C (1975) Salvadourea new urea derivative from Salvadora Persica. Chem Ind 12: 517518.

21. Sher H, Al-Yemeni $M$ N, Yahya S M, Arif H S (2010) Ethnomedicinal and ecological evaluation of Salvadora persica L: A threatened medicinal plant in Arabian Peninsula. J Med Plants Res 4: 1209-1215.

22. Saleem M, Kim H J, Ali M S, Lee Y S (2005) An update on bioactive plant lignans. Nat Prod Rep 22: 696-716.

\section{How to cite this article:}

Dipeshkumar Patel and Falaknaaz Shaikh. 2021. Invitro Antimicrobial and Antioxidant Activities of Salvadora persica (Meswak) Roots, Leaves and Stems Extracts. Int.J.Curr.Microbiol.App.Sci. 10(09): 498-509. doi: https://doi.org/10.20546/ijcmas.2021.1009.058 